\title{
Analysis of femoral fracture post motor vehicle accidents
}

Abdullah A. AlTurki, MBBS, Khalid S. AlAqeely, MBBS, Turki S. AlMugren, MBBS, Ibrahim S. AlZimami, MBBS.

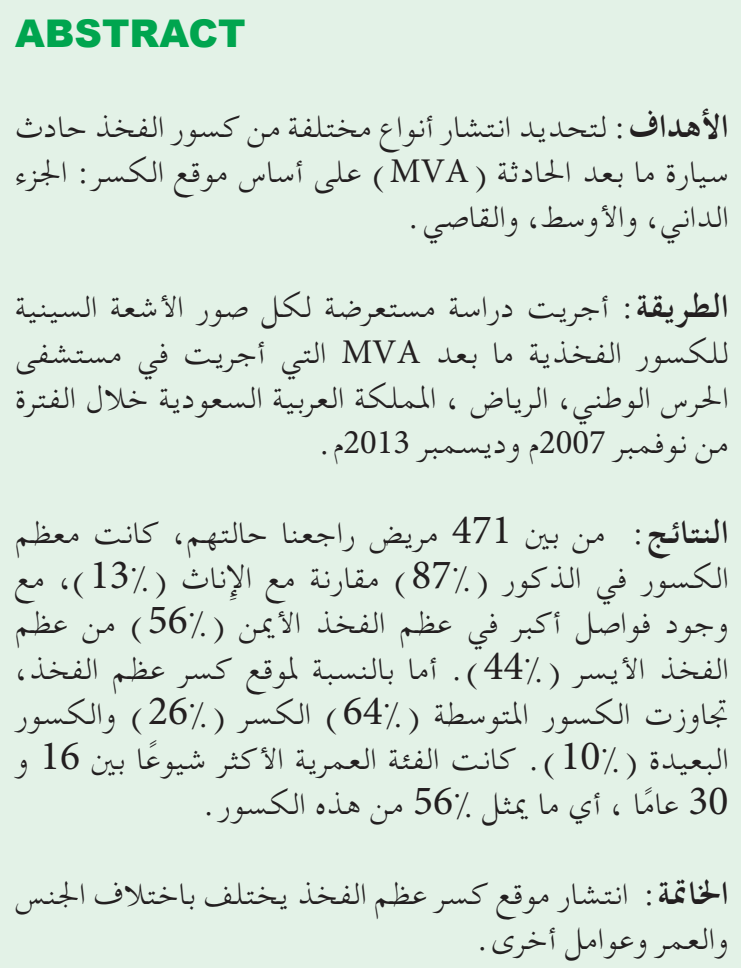

Objectives: To identify the prevalence of different types of femoral fractures post-motor vehicle accident (MVA) based on fracture location: proximal, middle and distal.

Methods: A cross-sectional study of all femoral fracture post-MVA $\mathrm{x}$-ray charts carried out at the National Guard Hospital, Riyadh, Kingdom of Saudi Arabia between November 2007 to December 2013.

Results: Among the 471 patients reviewed, most fractures were in male (87\%) compared with female $(13 \%)$ victims, with breaks more in the right femur (56\%) than the left femur (44\%). As for location of the femur fracture, middle fractures $(64 \%)$ exceeded proximal $(26 \%)$ and distal fractures (10\%). The most common age group was between $16-30$ years, representing $56 \%$ of these fractures.
Conclusion: Prevalence of the femur fracture location varies depending on gender, age, and other factors.

Saudi Med J 2019; Vol. 40 (1): $41-44$ doi: 10.15537/smj.2019.1.21547

From the Department of Surgery (Alturki, AlAqeely, AlMugren), Orthopedic Division, King Abdulaziz Medical City, National Guard Health Affairs, and from the Department of Family Medicine (Alzimami), Prince Sultan Military Medical City, Riyadh, Kingdom of Saudi Arabia.

Received 16th August 2018. Accepted 29th October 2018.

Address correspondence and reprint request to: Dr. Abdullah A. Alturki, Department of Surgery, Orthopedic Division, King Abdulaziz Medical City, National Guard Health Affairs, Riyadh, Kingdom of Saudi Arabia.E-mail: alturki10@hotmail.com

ORCID ID: http://orcid.org/0000-0002-1403-4901

$\mathrm{T}$ he femur is the largest, longest, and strongest bone in the human skeleton. ${ }^{1}$ The femur articulates with the above acetabulum to form the hip joint and below the tibia and patella to form the knee joint. The upper end of the femur has a head, neck, and greater and lesser trochanter. The head forms approximately two-third of the sphere. The neck connects the head to the shaft, passing downward, backward and laterally to make an angle of approximately 125 degrees (slightly less in females) with the long axis of the shaft. Femoral shaft becomes broader toward its distal end, forming a flat, triangular area on its posterior surface called the popliteal surface. The lower end of the femur has 2 condyles (lateral and medial), separated posteriorly by the intercondylar notch. The anterior surfaces of the condyles are joined by an articular surface for the patella. ${ }^{2}$ There are many risk factors for a femoral fracture including: advanced age, postmenopausal, osteoporosis, decreased muscle mass and participation in certain contact sports such as football. ${ }^{3}$ In patients with normal bone strength, the most common causes of femur fractures includes motor vehicle accidents and falls from a height. ${ }^{4}$ Fractures of 
the femur are categorized by the exact location of the fracture. The first type is proximal femoral fractures, also called hip fractures. They involve the upper most portion of the femur bone just adjacent to the hip joint. The second type is shaft fracture that generally occurs in high-speed MVA or falls from a height. The third type is distal femoral fractures, also called supracondylar femur fracture, an injury to the thigh bone just above the knee joint. This fracture can involve the cartilage surface of the knee joint, which puts the patient at risk of developing knee arthritis later in life. ${ }^{5}$ Studies showed that the incidence of femoral fractures was reported as 9.5-18.9 fractures per 100,000 populations per year. ${ }^{6}$ In individuals younger than 25 years and those older than 65 years, the rate of femoral fractures is 3 per 10,000 population annually. These injuries are most common in males younger than 30 years. ${ }^{7}$ The World Health Organization (WHO) reported that, 1.2 million people die annually in road traffic accidents worldwide, with millions more sustaining severe, debilitating injuries. ${ }^{8}$ Femoral fracture has been a common presentation, with shaft fractures the most frequent area involved. ${ }^{9}$ Of patients injured during an MVA, 19-35.4\% will have femoral fracture. ${ }^{10,11}$

The aim of this study was to identify the prevalence of different types of femoral fractures post-MVA at the National Guard Hospital in Riyadh, Kingdom of Saudi Arabia from November 2007 to December 2013. We also sought to compare femoral fracture prevalence in the National Guard Hospital against worldwide prevalence. The identification of the femoral fracture types was based on the location of the fracture. We classified the fracture into proximal, middle, and distal. The proximal fracture extends to $5 \mathrm{~cm}$ below the lesser trochanter, the middle ends $9 \mathrm{~cm}$ above the knee joint, and the distal forms the last $9 \mathrm{~cm}$ of the femur.

Methods. We conducted a cross-sectional chart review study of all patients with $\mathrm{x}$-rays confirming femoral fracture post-MVA carried out at the National Guard Hospital, Riyadh, Kingdom of Saudi Arabia between November 2007 to December 2013. There were no exclusion criteria. The proper sample size was calculated by using an online sample size calculator (http://www.raosoft.com/samplesize). With a general $10 \%$ margin of error, $95 \%$ confidence and $50 \%$

Disclosure. Authors have no conflict of interests, and the work was not supported or funded by any drug company. prevalence, the recommended sample size was 94 patients. To strengthen the study, we included all the patients $(n=471)$ and used none probability consecutive sampling technique. From the chart, we acquired the age and gender for each patient. From the radiographic data, we acquired side, type, and measure of the exact locations for each fracture. The data was entered into an Excel sheet, then analyzed and interpreted by statistic program for analysis Statistical Package for Social Science Version 19 (Armonk, NY: IBM Corp.).

Patient data included: medical record number (subject number), age and gender of the patient, date of the x-ray, anatomical site of fracture, and its site. Qualitative data included frequencies and percentages of the fractures. Inferential statistics for comparison included Chi-square to compare the proportion of positive fractures by gender and age group with a statistical significance of $p \leq 0.05$.

Results. The majority of fractures were in male patients $(\mathrm{n}=411,87 \%)$ compared with female fractures $(\mathrm{n}=60,13 \%)$ (Table 1). Most fractures were on the right side $(n=266,56 \%)$ versus $(n=205,44 \%)$ on the left side. According to our criteria, the proximal fractures were almost 124 cases $(26 \%)$, the middle fractures had the highest percentage of fractures $(n=303,64 \%)$ and the least number of fractures were the distal fractures $(\mathrm{n}=44,10 \%)$. Bilateral femur fractures were found in 13 patients; 2 were proximal, while 9 were in the middle and 2 fractures were distal.

The most common age group prone to femoral fracture was young patients age $16-30$ years $(n=263$, $56 \%$ ). This group was followed by patients from 31-45 years old $(n=84,18 \%)$ and the smallest age group prone to femoral fractures were elderly people from 76-99 years old $(n=6,1 \%)$.

Cross tabulation data between gender and type showed that the proximal femoral fracture percentage is higher in females $(n=21,35 \%)$ compared to male patients $(\mathrm{n}=86,25 \%)$ with a significant difference ( $p=0.038)$ (Table 2).

Regarding proximal fractures, we found 51 fractures above the lesser trochanter at the neck of the femur, head, the trochanter itself. Seventy-three fractures were within $5 \mathrm{~cm}$ below the lesser trochanter. Regarding the middle shaft of femur fractures, there were 50 fractures between $9-15 \mathrm{~cm}$ above the knee joint and 200 fractures between $16-25 \mathrm{~cm}$, which is the most common site, while there were 53 fractures between $26-35 \mathrm{~cm}$. Regarding the distal type, there were 18 fractures between $1-5 \mathrm{~cm}$ above the knee joint, while the other 26 fractures were within $6-9 \mathrm{~cm}$ from the knee joint. 
Table 1 - Demographic of femoral fracture of 471 patients.

\begin{tabular}{lrr}
\hline Characteristics & $\mathbf{n}(\%)$ \\
\hline Gender & & \\
Male & $411(87)$ \\
Female & $60(13)$ \\
Total & $471(100)$ \\
Side & & \\
Right & 266 & $(56)$ \\
Left & 205 & $(44)$ \\
Total & $471(100)$ \\
Type & & \\
Proximal & 124 & $(26)$ \\
Mid & 303 & $(64)$ \\
Distal & 44 & $(10)$ \\
Total & $471(100)$ \\
Age group & & \\
1-15 & $77(16)$ \\
16-30 & $263(56)$ \\
$31-45$ & 84 & $(18)$ \\
46-60 & 27 & $(6)$ \\
61-75 & 14 & $(3)$ \\
$76-99$ & 6 & $(1)$ \\
Total & $471(100)$ \\
\hline
\end{tabular}

Discussion. A study in Romania found that male patients' femoral fractures are more frequent (23 cases out of 104) while the female group were identified with only 11 cases out of 78 . While femoral shaft fractures are relatively homogenous distributed between the genders (15 male and 10 female patients), fractures of the proximal extremity are more often found in female patients $(n=8$, with only one in male patients). ${ }^{12}$ In comparison with our study, male patients are predominant with 411 versus 60 female patients. The femoral shaft fractures are relatively the same distribution (66\% in males versus 50\% females). Similarly, the proximal fractures are more often found in female patients (35\% versus $25 \%$ ). One statistics that did not match was cases with femoral shaft fractures: the Romanian study showed an overall mean age of 40.44, while our study's mean age was $26.59 .{ }^{12}$ Another study ${ }^{10}$ in Finland found that $75 \%$ of all femoral shaft fractures to be associated with road traffic accidents, most of them in the middle third (79\%). The highest age- and gender-specific incidences were seen in males from 15-24 years of age. Similarly, in our study, 69\% of the femoral fractures are mid-fractures.

We performed this study in King Abdulaziz Medical City in Riyadh, Kingdom of Saudi Arabia, Trauma Center at the National Guard Hospital, which deals with a lot of trauma cases, especially because its location is near highways. In addition, it was not a multicenter study; all patients were from the same region. In our study, patients prior to November 2007 were excluded
Table 2 - Site of fracture by gender in 471 patients.

\begin{tabular}{lccc}
\hline Gender & Proximal & Mid & Distal \\
\hline Male $(\mathrm{n}=411)$ & $25 \%$ & $66 \%$ & $9 \%$ \\
Female $(\mathrm{n}=60)$ & $35 \%$ & $50 \%$ & $15 \%$ \\
\hline
\end{tabular}

due to the lack of computerized data for these patients. We reviewed all patients starting from 1 November 2007 to 31 December 2013. Our measurements were manually taken from X-rays, and we avoided inaccurate calculations by giving them approximate ranges rather than fixed numbers during data analysis.

Considering patients with bilateral femoral fractures as 2 separated fractures was a limitation in our study and we suggest further studies to include this point.

In conclusion, our study confirms the increased prevalence of middle shaft femoral fracture, especially in young males with increasing prevalence on the right side. The predominance of these fractures at a young age coincides with the most common age for reckless driving. Increased prevalence for proximal fractures in the female group may be related to osteoporosis and needs further investigation in future studies. For further articles, we recommend multicenter studies involving many hospitals, adding more parameters besides age, gender, type and side of fracture and exact location. Further, we suggest comparing the prognoses and complications for each type.

We are considering a new study regarding the prevalence of neck of femur fracture concomitant with femoral shaft fracture. Our interest specifically includes prevalence of neck versus femur fracture post-MVA.

Acknowledgment. The authors gratefully acknowledge English Trackers (HK) Co. Ltd. (www.englishtrackers.com), Wanchai, Hongkong for English language editing.

\section{References}

1. Hogan TM. Hip and femur. In: Hart RG, Rittenberry TJ, Uehara DT, editors. Handbook of Orthopaedic Emergencies. Philadelphia (PA): Lippincott Williams \& Wilkins; 1999. p. 307-308.

2. Snell RS. Clinical Anatomy by Systems. Philadelphia (PA): Lippincott Wiliams \& Wilkins; 2007. p. 349-350

3. Spears GN, Owen JT. The etiology of trochanteric fractures of the femur. J Bone Joint Surg Am 1949; 31A: 548-552.

4. Sadic S, Custovic S, Smajic N, Fazlic M, Vujadinovic A, Hrustic A, et al. Complications and functional recovery in treatment of femoral shaft fractures with unreamed intramedullary nailing. Med Arch 2014; 68: 30-33.

5. EVANS FG, PEDERSEN HE, LISSNER HR. The role of tensile stress in the mechanism of femoral fractures. $J$ Bone Joint Surg Am 1951; 33-A: 485-501. 
6. Nikolaou VS, Stengel D, Konings P, Kontakis G, Petridis G, Petrakakis G, et al. Use of femoral shaft fracture classification for predicting the risk of associated injuries. J Orthop Trauma 2011; 25: 556-559.

7. Ensrud KE. Epidemiology of fracture risk with advancing age. J Gerontol A Biol Sci Med Sci 2013; 68: 1236-1242.

8. World Health Organization. Road traffic injuries [Internet]. [Updated 2018]. Available from: https://www.who.int/en/ news-room/fact-sheets/detail/road-traffic-injuries

9. Salminen ST, Pihlajamäki HK, Avikainen VJ, Böstman OM. Population based epidemiologic and morphologic study of femoral shaft fractures. Clin Orthop Relat Res 2000; 241-249.
10. Singer BR, McLauchlan GJ, Robinson CM, Christie J. Epidemiology of fractures in 15,000 adults: the influence of age and gender. J Bone Joint Surg Br 1998; 80: 243-248.

11. Eluwa M, Wonwu V, Ekong M, Ekanem T, Akpantah A. Disposition of fractures and dislocations among road accident victims in rivers and bayelsa states of Nigeria from 1992-2005. The Internet Journal of Epidemiology 2009; 8: 1-4.

12. Kouris G, Hostiuc S, Negoi I. Femoral fractures in road traffic accidents. Rev Med Leg 2012; 20: 279-282. 